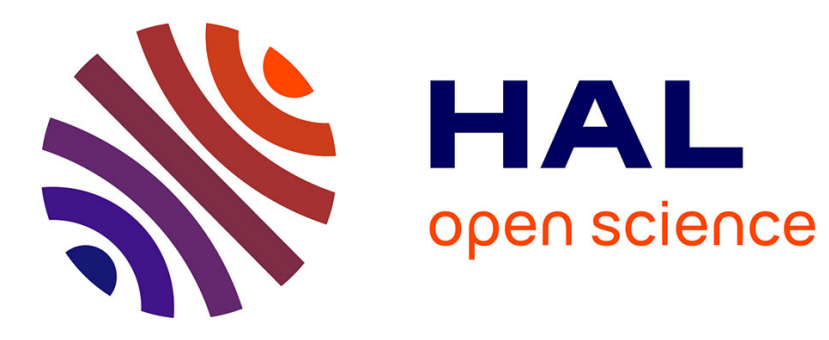

\title{
Influence of an Inorganic Interlayer on Exciton Separation in Hybrid Solar Cells
}

\author{
Claire L Armstrong, Michael B Price, David Munoz-Rojas, Nathaniel J K L \\ Davis, Mojtaba Abdi-Jalebi, Richard H Friend, Neil C Greenham, Judith L \\ Macmanus-Driscoll, Marcus L Böhm, Kevin P Musselman
}

\section{To cite this version:}

Claire L Armstrong, Michael B Price, David Munoz-Rojas, Nathaniel J K L Davis, Mojtaba AbdiJalebi, et al.. Influence of an Inorganic Interlayer on Exciton Separation in Hybrid Solar Cells. ACS Nano, 2015, 9 (12), pp.11863-11871. 10.1021/acsnano.5b05934 . hal-02012952

\section{HAL Id: hal-02012952 https://hal.science/hal-02012952}

Submitted on 9 Feb 2019

HAL is a multi-disciplinary open access archive for the deposit and dissemination of scientific research documents, whether they are published or not. The documents may come from teaching and research institutions in France or abroad, or from public or private research centers.
L'archive ouverte pluridisciplinaire $\mathbf{H A L}$, est destinée au dépôt et à la diffusion de documents scientifiques de niveau recherche, publiés ou non, émanant des établissements d'enseignement et de recherche français ou étrangers, des laboratoires publics ou privés. 


\title{
Influence of an Inorganic Interlayer on Exciton Separation in Hybrid Solar Cells
}

\author{
Claire L. Armstrong, ${ }^{\dagger}$ Michael B. Price, ${ }^{\ddagger}$ David Muñoz-Rojas, ${ }^{\dagger, \S}$ Nathaniel J. K. L. Davis, ${ }^{\ddagger}$ \\ Mojtaba Abdi-Jalebi, ${ }^{\ddagger}$ Richard H. Friend, ${ }^{\ddagger}$ Neil C. Greenham, ${ }^{\ddagger}$ Judith L. MacManus-Driscoll, ${ }^{\dagger}$ \\ Marcus L. Böhm, ${ }^{*, \neq}$ and Kevin P. Musselman ${ }^{\ddagger, \|}$
}

${ }^{\dagger}$ Department of Materials Science and Metallurgy, University of Cambridge, 27 Charles Babbage Road, CB3 OFS, Cambridge, U.K., ' Cavendish Laboratory, University of Cambridge, J.J. Thomson Avenue, Cambridge, CB3 OHE, U.K., 'Laboratoire des Matériaux et du Génie Physique, Université Grenoble-Alpes, CNRS, 3 Parvis Louis Néel, 38016 Grenoble, France, and "Department of Mechanical and Mechatronics Engineering, University of Waterloo, 200 University Avenue West, Waterloo, Ontario N2L 3G1, Canada

\begin{abstract}
It has been shown that in hybrid polymerinorganic photovoltaic devices not all the photogenerated excitons dissociate at the interface immediately, but can instead exist temporarily as bound charge pairs (BCPs). Many of these BCPs do not contribute to the photocurrent, as their long lifetime as a bound species promotes various charge carrier recombination channels.
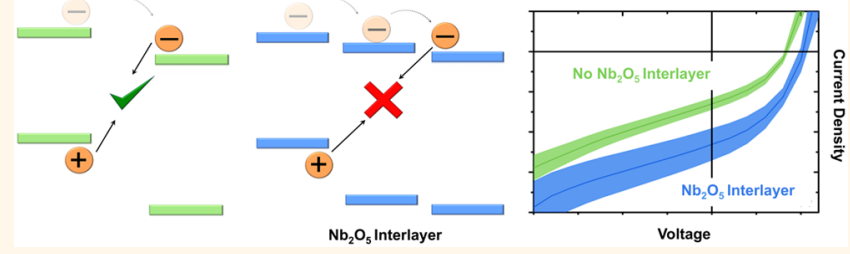

Fast and efficient dissociation of BCPs is therefore considered a key challenge in improving the performance of polymer-inorganic cells. Here we investigate the influence of an inorganic energy cascading $\mathrm{Nb}_{2} \mathrm{O}_{5}$ interlayer on the charge carrier recombination channels in poly(3-hexylthiophene-2,5diyl) ( $\mathrm{P3} \mathrm{HT})-\mathrm{TiO}_{2}$ and $\mathrm{PbSe}$ colloidal quantum dot $-\mathrm{TiO}_{2}$ photovoltaic devices. We demonstrate that the additional $\mathrm{Nb}_{2} \mathrm{O}_{5}$ film leads to a suppression of $\mathrm{BCP}$ formation at the heterojunction of the $\mathrm{P} 3 \mathrm{HT}$ cells and also a reduction in the nongeminate recombination mechanisms in both types of cells. Furthermore, we provide evidence that the reduction in nongeminate recombination in the $\mathrm{P} 3 \mathrm{HT}-\mathrm{TiO}_{2}$ devices is due in part to the passivation of deep midgap trap states in the $\mathrm{TiO}_{2}$, which prevents trap-assisted Shockley-Read-Hall recombination. Consequently a significant increase in both the open-circuit voltage and the short-circuit current was achieved, in particular for P3HT-based solar cells, where the power conversion efficiency increased by $39 \%$.
\end{abstract}

KEYWORDS: atmospheric pressure spatial atomic layer deposition $\cdot$ metal oxide $\cdot$ recombination $\cdot$ solar cell $\cdot$ energy cascade $\cdot \mathrm{Nb}_{2} \mathrm{O}_{5}$

$\longrightarrow$ ver the past decade there has been extensive research into organic/ inorganic hybrid solar cells as a low-cost and scalable photovoltaic technology. ${ }^{1-5}$ For a polymer-metal oxide hybrid solar cell, for example, the flexibility and high absorption coefficient of the polymer are combined with the stability, carrier mobility, and band gap tunability of the metal oxide. In addition, the metal oxide can be deposited by a variety of different methods and can also be nanostructured to tune the heterojunction between the organic and metal oxide. ${ }^{6-11}$ The mixed materials deployed in hybrid solar cells therefore provide a large degree of parameter customizability that cannot be achieved in all-organic or all-inorganic cells. Despite these advantages, hybrid organic-inorganic cells are still outperformed by all-organic cells. It is likely that an inefficient charge carrier separation at the polymer-metal oxide interface is the predominant reason for the lower device performance. ${ }^{2,3}$ Originally, it was believed that charge separation at the organicinorganic interface produces free charge carrier pairs instantly. Recent studies, however, have shown that the efficiency of such a charge transfer process from the polymer to the metal oxide can vary with the properties of the oxide. ${ }^{12}$ The electron transfer process in organic-inorganic solar cells from a p-type donor polymer into an n-type metal oxide has been shown to produce a large proportion of charge carrier pairs, which remain entangled across the interface. ${ }^{13-15}$ Due to their Coulombic attraction, these bound charge carrier pairs (BCPs) are prone to recombination effects, which have been demonstrated to significantly limit the device performance of hybrid solar cells. ${ }^{13,15-17}$ To drive the separation of charges at the interface, strategies such as the incorporation of organic modifiers, ${ }^{18,19}$

\section{* Address correspondence to mb842@cam.ac.uk.}

Received for review July 7, 2015 and accepted November 8, 2015.

Published online November 08, 2015 10.1021/acsnano.5b05934

(C) 2015 American Chemical Society 
(a)

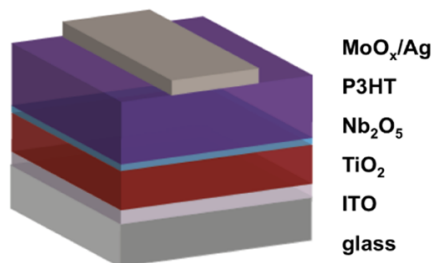

(b)

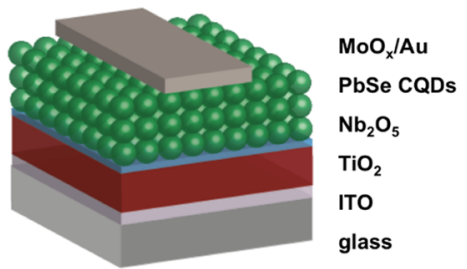

(c)

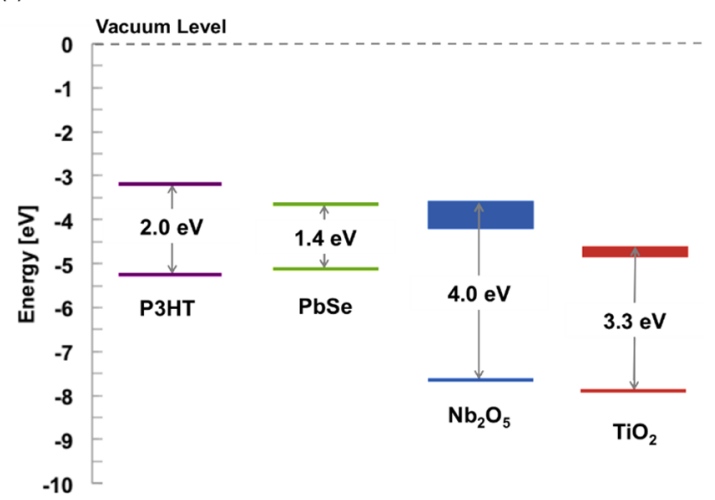

Figure 1. Schematic device architecture of solar cells employing (a) $\mathrm{P} 3 \mathrm{HT}$ or (b) PbSe CQDs as photoactive material where $\mathrm{a} \sim 10 \mathrm{~nm}$ thick $\mathrm{Nb}_{2} \mathrm{O}_{5}$ film is used as an energy cascading interlayer. (c) Band energy alignment of a $\mathrm{P} 3 \mathrm{HT} / \mathrm{Nb}_{2} \mathrm{O}_{5} / \mathrm{TiO}_{2}$ and a $\mathrm{PbSe} \mathrm{CQD} / \mathrm{Nb}_{2} \mathrm{O}_{5} / \mathrm{TiO}_{2}$ cascade structure as determined by ultraviolet photoelectron spectroscopy and absorbance spectroscopy.

dyes, $^{20,21}$ self-assembled monolayers, ${ }^{16,17}$ and doping of the metal oxide ${ }^{12}$ have been reported.

An alternative approach is to suppress the initial formation of BCPs using energy cascade structures, where an interlayer between the light-absorbing p-type material and the electron-accepting n-type provides a gradient in the conduction band levels. The larger transfer integral due to the improved alignment of donor and acceptor states results in fast electron transfer across the interface, ${ }^{22}$ and the larger spatial separation of the bound electron-hole pair has been shown to suppress the formation of BCPs, as the electron and hole are pushed out of their respective Coulomb capture radii, creating free charge carriers directly. ${ }^{23}$ While such energy cascade structures have been shown to improve the solar cell device performance, ${ }^{18,19,22-31}$ it remains challenging to implement them on large scales due to inconvenient processing conditions. ${ }^{23}$ Notably, while organic modifiers that produce energy cascade structures have been shown to prevent BCP formation, ${ }^{13,17}$ similar mitigation of BCPs using more robust inorganic layers has not been demonstrated.

Here we deploy a stable and rapidly processable $\mathrm{Nb}_{2} \mathrm{O}_{5}$ energy cascade interlayer in $\mathrm{P} 3 \mathrm{HT}-\mathrm{TiO}_{2}$ and $\mathrm{PbSe}$ colloidal quantum dot (CQD) $-\mathrm{TiO}_{2}$ solar cells. The layers are fabricated using atmospheric pressure spatial atomic layer deposition (AP-SALD), a recent variation of ALD offering ambient pressure processing and accelerated deposition rates. ${ }^{32}$ Using transient photovoltage, transient absorption, photothermal deflection spectroscopy, and light-dependent photovoltage measurements, we confirm that the inorganic interlayer indeed suppresses various recombination channels such as nongeminate and BCP recombination. Furthermore, we present evidence that the interlayer also passivates trap states in the $\mathrm{TiO}_{2}$, specifically reducing nongeminate Shockley-Read-Hall recombination.

\section{RESULTS AND DISCUSSION}

Solar cells were fabricated by sequential deposition of $\mathrm{TiO}_{2}(\sim 90 \mathrm{~nm})$ and $\mathrm{Nb}_{2} \mathrm{O}_{5}(\sim 10 \mathrm{~nm})$ films onto ITO/glass substrates by AP-SALD. The photoactive film (either P3HT or PbSe CQDs) was applied using spincoating methods, and the top electrode $\left(\mathrm{MoO}_{x}\right.$ and $\mathrm{Ag} / \mathrm{Au}$ ) was then thermally evaporated. The typical device architectures are illustrated schematically in Figure $1 \mathrm{a}$ and $\mathrm{b}$. A detailed description of the fabrication methods can be found in the Experimental Section.

Employing X-ray diffraction (XRD) and X-ray photoelectron spectroscopy (XPS) to characterize the $\mathrm{TiO}_{2}$ and $\mathrm{Nb}_{2} \mathrm{O}_{5}$ films, we identify polycrystalline $\mathrm{TiO}_{2}$ films consisting of the anatase phase (see Supporting Information S1). Examination of the XRD measurements conducted on $\mathrm{Nb}_{2} \mathrm{O}_{5}$ films reveals no diffraction peaks, suggesting an amorphous $\mathrm{Nb}_{2} \mathrm{O}_{5}$ structure. Analyzing the corresponding chemical binding energies via

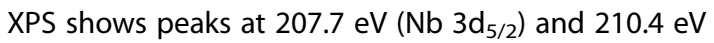
$\left(\mathrm{Nb} 3 \mathrm{~d}_{3 / 2}\right)$, which confirms the presence of $\mathrm{Nb}$ in the $5+$ oxidation state. ${ }^{27}$ Using UV-photoelectron spectroscopy (UPS) and absorbance spectroscopy we measure the electron affinity of $\mathrm{Nb}_{2} \mathrm{O}_{5}$ to be smaller than $\mathrm{TiO}_{2}$, but larger than $\mathrm{P} 3 \mathrm{HT}$ and $\mathrm{PbSe}$ CQDs, confirming the energy cascading nature of the conduction bands in the studied material arrangements (see Figure 1c). ${ }^{33}$ All raw spectra (XRD, XPS, UPS, and absorbance) can be found in the Supporting Information S1 and S2.

Current density-voltage $(J-V)$ curves demonstrating the average cell performance under simulated AM1.5G illumination are shown in Figure 2, with the average and highest efficiency cell performance parameters presented in Table 1. The open-circuit voltage and short-circuit current density were improved for both the $\mathrm{P} 3 \mathrm{HT} / \mathrm{TiO}_{2}$ and $\mathrm{PbSe} / \mathrm{TiO}{ }_{2}$ cell designs upon introduction of the $\mathrm{Nb}_{2} \mathrm{O}_{5}$ interlayer. The average fill factors were unchanged (within experimental uncertainty). 

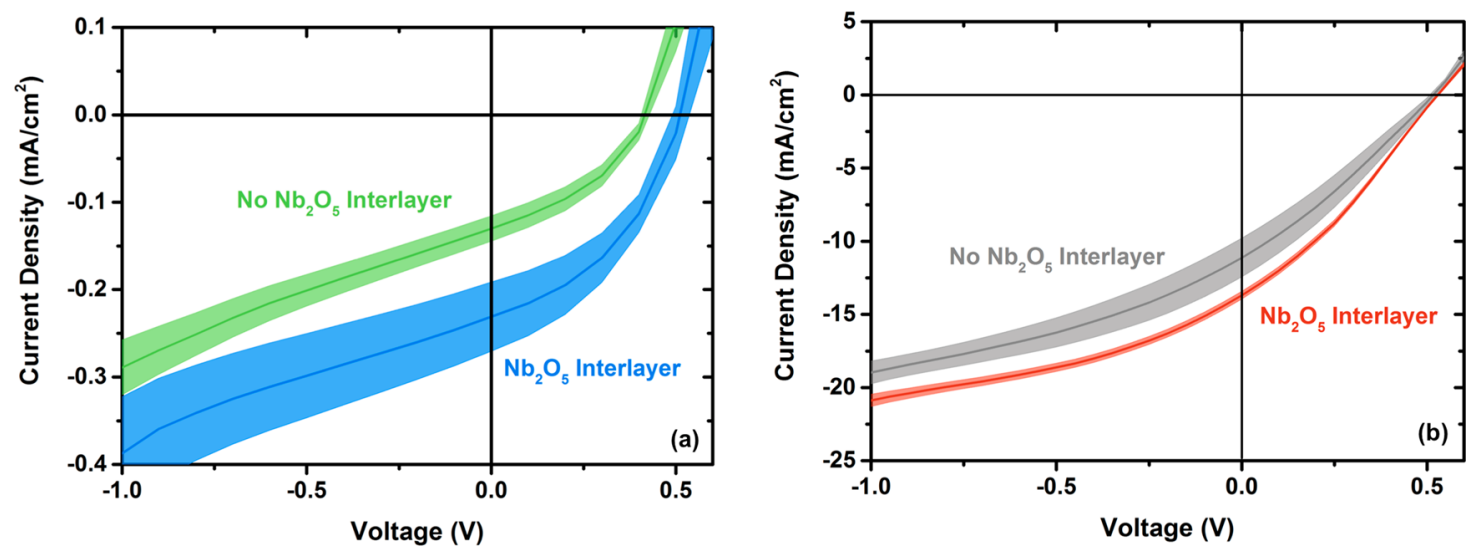

Figure 2. Current density-voltage curves for (a) $\mathrm{P} 3 \mathrm{HT}$ cells and (b) PbSe CQD cells with and without the $\mathrm{Nb}_{2} \mathrm{O}_{5}$ interlayer, under AM1.5 solar simulator conditions $\left(100 \mathrm{~mW} \mathrm{~cm}{ }^{-2}\right)$. We show the average performance of multiple independent solar cells in dark lines and the spread as a shaded area around the mean.

TABLE 1. Average $V_{\mathrm{oc}} J_{\mathrm{sc}} \mathrm{FF}$, and Power Conversion Efficiency (PCE) of P3HT and PbSe CQD Devices under AM1.5 Solar Simulator Conditions $\left(100 \mathrm{~mW} \mathrm{~cm}^{-2}\right)^{a}$

\begin{tabular}{lllll} 
& \multicolumn{1}{c}{$\boldsymbol{V}_{\mathbf{~ o c}}(\mathbf{V})$} & \multicolumn{1}{c}{$\boldsymbol{J}_{\mathbf{s c}}\left(\mathbf{m A} / \mathbf{c m}^{2}\right)$} & FF & PCE (\%) \\
\hline $\mathrm{P} 3 \mathrm{HT} / \mathrm{TiO}_{2}$ & $0.47 \pm 0.02(0.41)$ & $0.18 \pm 0.02(0.29)$ & $0.44 \pm 0.02(0.57)$ & $0.036 \pm 0.003(0.068)$ \\
$\mathrm{P3HT} / \mathrm{Nb}_{2} \mathrm{O}_{5} / \mathrm{TiO}_{2}$ & $0.56 \pm 0.01(0.51)$ & $0.26 \pm 0.02(0.40)$ & $0.40 \pm 0.02(0.49)$ & $0.050 \pm 0.005(0.100)$ \\
average improvement & $19 \%$ & $44 \%$ & $-9 \%$ & $39 \%$ \\
$\mathrm{PbSe} / \mathrm{TiO}_{2}$ & $0.49 \pm 0.01(0.51)$ & $11.1 \pm 1.3(14.7)$ & $0.28 \pm 0.02(0.37)$ & $1.68 \pm 0.28(2.81)$ \\
${\mathrm{PbSe} / \mathrm{Nb}_{2} \mathrm{O}_{5} / \mathrm{TiO}_{2}}^{0.53 \pm 0.01(0.54)}$ & $13.9 \pm 0.2(15.5)$ & $0.30 \pm 0.04(0.32)$ & $2.25 \pm 0.05(2.68)$ \\
average improvement & $8 \%$ & $25 \%$ & $10 \%$ & $34 \%$
\end{tabular}

${ }^{a}$ The performance of the respective highest efficiency device is shown in parentheses.

We note that prepared $\mathrm{P} 3 \mathrm{HT} / \mathrm{Nb}_{2} \mathrm{O}_{5}$ cells without the $\mathrm{TiO}_{2}$ film as an electron-accepting layer showed poor device performance because of negligible photocurrent, likely due to the significant increase in series resistance when the $\mathrm{TiO}_{2}$ layer is replaced by the dielectric $\mathrm{Nb}_{2} \mathrm{O}_{5} \cdot{ }^{34-36}$ We therefore argue that only the combination of $\mathrm{TiO}_{2}$ and $\mathrm{Nb}_{2} \mathrm{O}_{5}$ (giving rise to the energy cascade and subsequent reduction in interfacial recombination) leads to an efficiency enhancement (see Supporting Information S3).

Comparing the polymer-based solar cells with the fabricated CQD devices we find a significantly larger enhancement of $V_{\text {oc }}$ and $J_{\text {sc }}$ in the P3HT cells (i.e., $19 \%$ and $44 \%$ versus $8 \%$ and $25 \%$ for $V_{\text {oc }}$ and $J_{\text {sc }}$, respectively), even though the $\mathrm{Nb}_{2} \mathrm{O}_{5}$ interlayer was of identical thickness in both device architectures. A similar improvement in device performance has been observed for all-polymer solar cells where a polymeric energy cascade was provided. ${ }^{23}$ In that report the authors argued that a suppression of recombination mechanisms could be considered as the origin for the observed performance improvement. To investigate whether similar arguments can explain the apparent difference in device performance between the P3HT- and PbSe CQD-based solar cells, we first study the nongeminate recombination dynamics of both device structures by following the transient photovoltage (TPV) decay under constant white light background illumination (see Figure 3).
For TPV measurements the device was held at open-circuit voltage and the voltage decay transient was recorded after the device was subjected to a small perturbative monochromatic light pulse from an LED. The intensity of the pulse was chosen such that the resulting change in voltage $(\delta V)$ compared to the $V_{\text {oc }}$ was small $(<5 \%)$ (the $V_{\text {oc }}$ was produced by constant white-light background illumination). For the extraction of the decay constants we applied mono- and biexponential fits. The TPV decay of the PbSe CQDbased cells with and without the inorganic interlayer could be modeled accurately using a monoexponential fitting routine. In contrast, a biexponential fit was needed to derive accurate decay constants for the P3HT cells (see Figure 3 ). For cells consisting of PbSe CQDs we see a mild increase in the TPV decay times from $3.09 \pm 0.01 \mathrm{~ms}$ to $4.65 \pm 0.02 \mathrm{~ms}$ once the inorganic interlayer is applied. This behavior suggests that the observed photovoltage decay is due, at least in part, to interfacial recombination ${ }^{37}$ and that interfacial recombination can be suppressed by spatially separating the charges at the interface (electrons in $\mathrm{TiO}_{2}$ and holes in the CQDs). A similar increase in the fast decay component $\tau_{1}$ is also observed in the P3HT cells when the interlayer is incorporated ( $15.6 \pm 0.2$ to $33.1 \pm 0.2 \mathrm{~ms}$ ), indicating again that the interlayer prevents interfacial recombination. We therefore tentatively assign the increased decay times and the entailed reduction in 

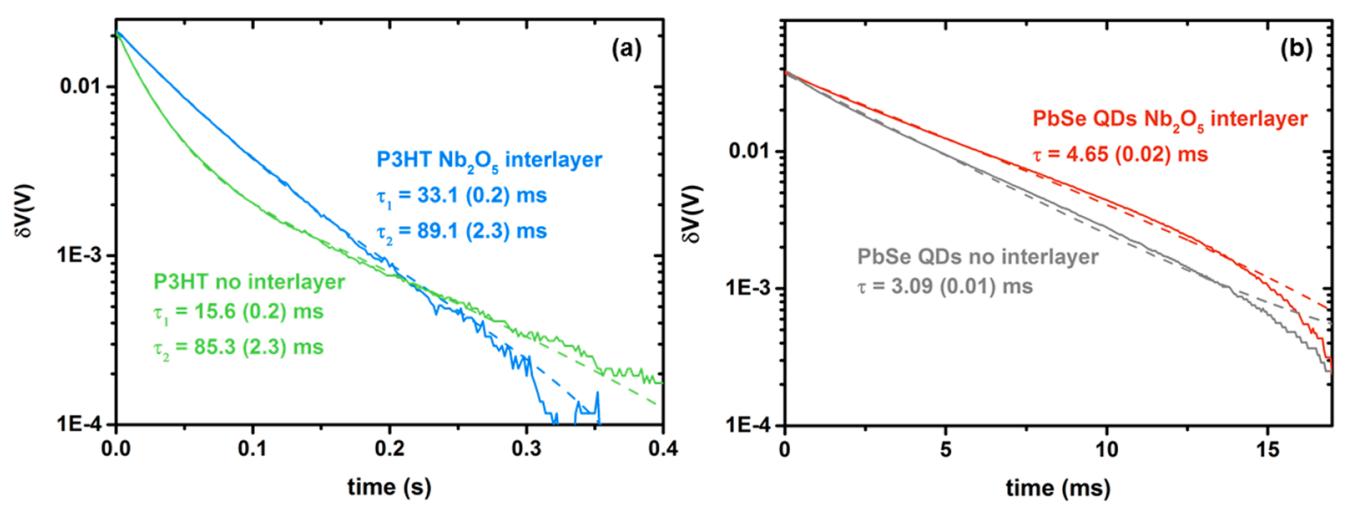

(b)

Figure 3. Transient photovoltage decay measurements on (a) P3HT and (b) PbSe CQD solar cells with and without the interlayer under constant white-light background illumination $\left.(33 \mathrm{~mW} \mathrm{~cm})^{-2}\right)$. Solid lines show the measured photovoltage decay, and the dashed lines represent the applied exponential fits. Values in brackets are the errors for the fitted time constants. Further analysis and details of the fitting routines used can be found in the Supporting Information S4.

recombination rate to the spatial separation of electrons and holes by the energy cascade, which reduces the Coulombic attraction of opposite charges across the interface. ${ }^{18,19,22-31}$

The biexponential nature of the decay in the $\mathrm{P} 3 \mathrm{HT}$ devices highlights the significance of multiple nongeminate recombination mechanisms. Considering the omnipresence of electron acceptor states below the conduction band in as-prepared $\mathrm{TiO}_{2}$ films (see Supporting Information S5), ${ }^{38,39}$ we suggest that the additional $\mathrm{Nb}_{2} \mathrm{O}_{5}$ layer may also perform as a passivating agent for these acceptor states. Due to their localized nature, electron acceptor states are likely to promote additional, nongeminate recombination channels such as Shockley-Read-Hall-type recombination (SRH). If the density of these localized acceptor states is reduced (e.g., through a potential passivating agent such as $\mathrm{Nb}_{2} \mathrm{O}_{5}$ ), we would expect a much less pronounced second TPV decay component. Indeed, while the decay constant $\tau_{2}$ remains relatively unchanged for the $\mathrm{P} 3 \mathrm{HT}$ cells $(89.1 \pm 2.3$ and $85.2 \pm 2.3 \mathrm{~ms}$ with and without the interlayer, respectively), we find that in devices with a $\mathrm{Nb}_{2} \mathrm{O}_{5}$ layer it does not become the dominant decay channel until much smaller voltages (see Supporting Information S4). In other words, a much smaller percentage of the charges recombine via this slower mechanism when the interlayer is present. We associate this finding with a still detectable but significantly reduced density of electron acceptor states in the $\mathrm{TiO}_{2}$ band gap when the $\mathrm{Nb}_{2} \mathrm{O}_{5}$ interlayer is introduced. Further evidence for this result comes from photothermal deflection spectroscopy, where we measure a sharper drop in absorbance in $\mathrm{Nb}_{2} \mathrm{O}_{5}$-modified $\mathrm{TiO}_{2}$ films compared to plain $\mathrm{TiO}_{2}$ samples (see Supporting Information S5). This steeper slope in absorbance is in agreement with a reduced density of midgap trap states. ${ }^{40}$

It should be noted that in dye-sensitized solar cells it has been shown that a thin film of $\mathrm{AlO}_{\mathrm{x}}$ between the sensitizer and electron acceptor can efficiently passivate trap states on the $\mathrm{TiO}_{2}$ surface, thereby increasing the solar cell efficiency. ${ }^{41,42}$ In such studies, the $\mathrm{AlO}_{\mathrm{x}}$ does not provide an energy cascade between the donor and acceptor. In independently prepared $\mathrm{P} 3 \mathrm{HT} / \mathrm{AlO}_{\mathrm{x}} /$ $\mathrm{TiO}_{2}$ solar cells we find inferior device performance, suggesting that passivation of $\mathrm{TiO}_{2}$ trap states alone cannot produce the observed increase in efficiency (see Supporting Information S6).

We note that the interlayer would similarly passivate such acceptor states on the $\mathrm{TiO}_{2}$ surface in the $\mathrm{PbSe}$ CQD cells. The comparatively good transport in the PbSe CQD layer $\left(\mu_{\mathrm{H}}=\sim 0.1 \mathrm{~cm}^{2} \mathrm{~V}^{-1} \mathrm{~s}^{-1}\right.$ in PbSe CQDs vs $\sim 10^{-4}-10^{-3} \mathrm{~cm}^{2} \mathrm{~V}^{-1} \mathrm{~s}^{-1}$ in $\left.\mathrm{P} 3 \mathrm{HT}\right),{ }^{43,44}$ however, is likely to promote faster nongeminate recombination mechanisms, such as Auger recombination and direct band-to-band recombination at the interface. However, at present we cannot discount the possibility that some interfacial recombination in the PbSe CQD cells occurs via trap states and that the observed increase in photovoltage decay time in these cells (which was attributed to a reduction in interfacial recombination with the introduction of the interlayer) may be due in part to the passivation of trap states on the $\mathrm{TiO}_{2}$ surface.

Further evidence for multiple operational recombination channels in the $\mathrm{P} 3 \mathrm{HT}$ devices without the $\mathrm{Nb}_{2} \mathrm{O}_{5}$ interlayer comes from steady-state $J V$ measurements where we monitor the open-circuit voltage $\left(V_{\text {oc }}\right)$ under different light intensities (see Figure 4). We find that P3HT devices without the interlayer exhibit a stronger dependence on light intensity (larger slope) than those with the interlayer. By expressing the slope of the $V_{\mathrm{OC}}$ as a function of logarithmic light intensity in increments of $k T / q$, we can obtain the ideality factor $n_{\mathrm{id}}$, which provides some indication for the recombination mechanisms present in the cell. ${ }^{45-47}$ As shown by Kirchartz and Nelson, the value of $n_{\text {id }}$ can be used to determine whether nongeminate recombination between free and trapped carriers (SRH-type) occurs via a shallow band tail (i.e., acceptor states close to the band edge) or deeper, midgap trap states. ${ }^{45}$ Assuming equal capture cross sections for electrons and holes, 


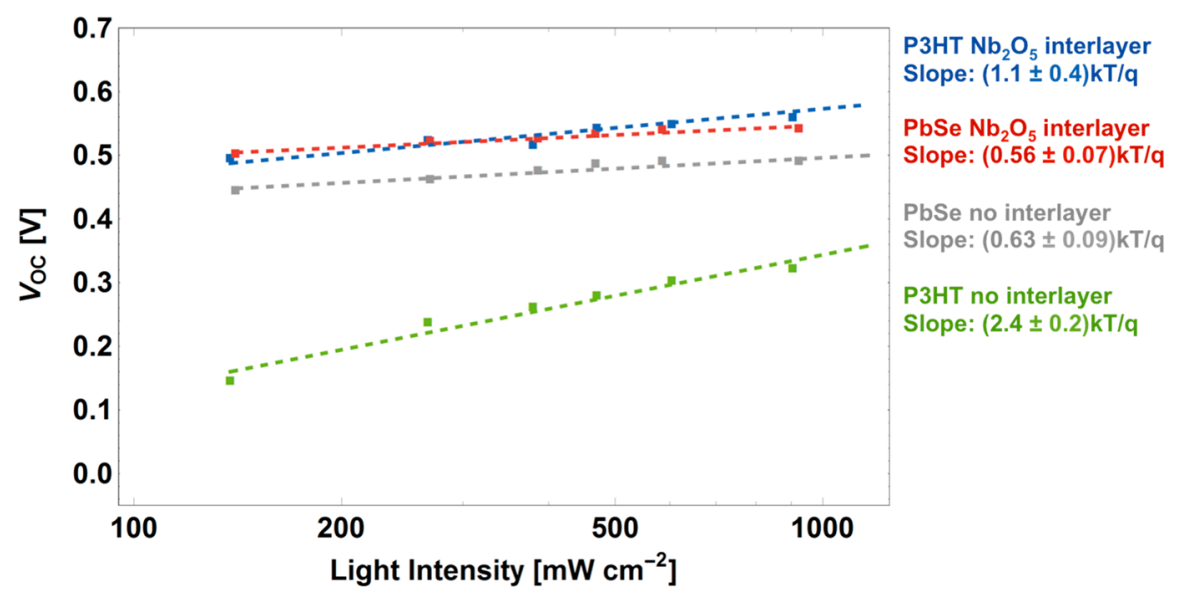

Figure 4. Dependence of $V_{o c}$ on light intensity for $\mathrm{P} 3 \mathrm{HT}$ and $\mathrm{PbSe} C Q D$ cells with and without a $\mathrm{Nb}_{2} \mathrm{O}_{5}$ interlayer.

SRH-type recombination via band tail states has been shown to produce $n_{\text {id }}$ values close to 1 . If recombination through midgap states becomes the dominant recombination channel, $n_{\text {id }}$ approaches $2 .{ }^{48}$ A mixture between deep and shallow trap-state-mediated recombination consequently produces $n_{\text {id }}$ values between 1 and 2 . We note that $n_{\text {id }}$ values exceeding 2 have also been observed in the literature and assigned to more complex recombination channels such as tunneling-enhanced bulk recombination, ${ }^{49}$ recombination due to local nonlinear shunts, ${ }^{50}$ and recombination at extended defect sites. ${ }^{51}$

For the P3HT-based cells we find a decrease in $n_{\text {id }}$ from $2.4 \pm 0.2$ to $1.1 \pm 0.4$ when the $\mathrm{Nb}_{2} \mathrm{O}_{5}$ interlayer is introduced, indicating that without the interlayer SRHtype recombination primarily occurs through midgap traps or proceeds via more complex recombination scenarios. ${ }^{45}$ We note that these devices also show $n_{\text {id }}$ values approaching 1 at high light intensities (see Figure 4; last data point). Such an unexpected change in ideality factor has been seen before and assigned to surface recombination at the contacts, which has been identified to be strongly favored under high light intensities when the minority carrier concentration is high. ${ }^{45}$

Upon introduction of the $\mathrm{Nb}_{2} \mathrm{O}_{5}$ interlayer, $n_{\text {id }}$ is decreased to 1.1 , suggesting a recombination mechanism that is no longer dominated by deep midgap trap states. This finding is consistent with the TPV results and aforementioned passivation of $\mathrm{TiO}_{2}$ surface states by the $\mathrm{Nb}_{2} \mathrm{O}_{5}$ interlayer.

We therefore conclude at this stage that the $\mathrm{Nb}_{2} \mathrm{O}_{5}$ interlayer suppresses midgap-state-mediated SRH-type recombination in the $\mathrm{P} 3 \mathrm{HT}$ cells (by passivating these states), such that the band-tail state-governed recombination channel is more prevalent and the solar cell performance is improved.

Examining the ideality factor of the CQD cells provides a completely different picture, where we observe a slight reduction in ideality from $0.63 \pm$ 0.09 to $0.56 \pm 0.07$ upon introduction of the $\mathrm{Nb}_{2} \mathrm{O}_{5}$ interlayer. In order to explain this trend in $n_{\mathrm{id}}$, we consider two phenomena that are intrinsic to quantum dots: first, the quantum confinement effect, which provides a correlation between the physical size of the CQD and its band gap, ${ }^{52,53}$ and second, the large surface-to-volume ratio of the nanometer-sized crystallites. ${ }^{54}$ The strong quantum confinement changes the kinetic interplay of recombination channels compared to bulk material, thus favoring multiparticle recombination channels such as Auger recombination. ${ }^{55-57}$ This process has been shown to produce ideality factors of $n_{\text {id }}=2 / 3$. $^{58}$ Furthermore, the large surface-to-volume ratio can generate a significant number of midgap trap states that are able to pin the Fermi level under operating solar cell conditions. ${ }^{59}$ The resulting light-intensity-independent evolution of $V_{\mathrm{OC}}$ has been shown to reduce the ideality factor further. ${ }^{48}$ We therefore interpret the unchanged and low ideality factors in the PbSe CQD cells as an indication that the recombination channels are predominantly governed by typical CQD-related processes (e.g., Auger-type- and CQD-surface-related phenomena) and are influenced less by the applied $\mathrm{Nb}_{2} \mathrm{O}_{5}$ interlayer, consistent with the smaller influence of the interlayer observed in the TPV measurements (Figure 3).

We therefore conclude at this stage that both P3HTand PbSe CQD-based solar cells show an overall reduction in nongeminate recombination when a cascade interlayer is introduced. We attribute this phenomenon to the energy level cascade, which drives the electrons away from the interface, thereby providing an efficient spatial barrier to interfacial recombination. In addition, trap-assisted recombination in $\mathrm{P} 3 \mathrm{HT}$ cells is reduced by the interlayer through the passivation of interfacial electron-accepting states on the $\mathrm{TiO}_{2}$, resulting in an improved $J_{\mathrm{SC}}$ and $V_{\mathrm{OC}}$ (Figure 2a).

While transient techniques with microsecond time resolution can provide insights into nongeminate recombination mechanisms, they cannot resolve faster processes such as the geminate-like recombination of BCPs. ${ }^{13,60}$ Since polymers like P3HT have lower charge densities and dielectric constants than inorganic 
CQDs, ${ }^{13,61}$ we expect a larger proportion of generated excitons to form BCPs at the interface between the polymer and metal oxide. As such BCPs are prone to recombination, ${ }^{13,17}$ it follows that the extractable photocurrent in these hybrid cells is highly dependent on the quantity of BCPs formed. We note that significant quantities of BCPs have been shown to build up at the $\mathrm{P} 3 \mathrm{HT}-\mathrm{TiO}_{2}$ interface using ultrasensitive steadystate absorbance techniques such as photothermal deflection spectroscopy (PDS). ${ }^{14}$ To study whether the introduced $\mathrm{Nb}_{2} \mathrm{O}_{5}$ interlayer has an influence on the formation of BCPs, we conduct ultrafast (picosecond time resolution) transient pump-push photocurrent spectroscopy measurements. In this extension of conventional transient absorption spectroscopy, the hybrid device is exposed to an optical "pump" pulse with an energy greater than the band gap (2.7 eV). This creates electron-hole pairs, which ideally separate at the polymer-metal oxide interface and which can be extracted to produce a photocurrent, $P_{c}$. If some charge carrier pairs temporarily remain at the interface as BCPs, a subsequent near-infrared "push" pulse (1.1 eV) can provide the energy necessary to separate the BCPs into free charges, thus generating additional photocurrent, $\delta P_{c} \cdot{ }^{13,23}$ Correlating the generated photocurrent with and without the additional push pulse as a function of the pump-push delay provides insight into the quantities and kinetics of $\mathrm{BCP}$ states formed at the interface (see Figure 5). No increase in photocurrent was observed in the $\mathrm{PbSe}$ CQD cells upon application of the push pulse, which is consistent with the absence of BCPs. In P3HT cells without an interlayer, however, we see a difference in the transient $\delta P_{\mathrm{c}} / P_{\mathrm{c}}$ signal. We assign this additional photocurrent contribution to $B C P s$, which are separated into free charges by the energy provided through the "push" pulse. This additional photocurrent decreases as the pump-push delay increases. We explain this decay with the BCPs having more time to recombine prior to the arrival of the "push" pulse. It follows that fewer BCPs can be split by the push pulse, and the contribution to the photocurrent decreases. Similar decay times ( $200 \mathrm{ps}$ ) have also been observed in other polymer/oxide hybrid devices and attributed to BCPs. ${ }^{13,17}$ Interestingly, we could not clearly distinguish the $\delta P_{\mathrm{c}} / P_{\mathrm{c}}$ signal from the noise floor $(4 \sigma$ threshold) once the interlayer was introduced, suggesting that fewer BCPs are formed at the interface. This finding is in agreement with our previous hypothesis that the energy cascade structure provides a sufficient driving force to efficiently direct electrons

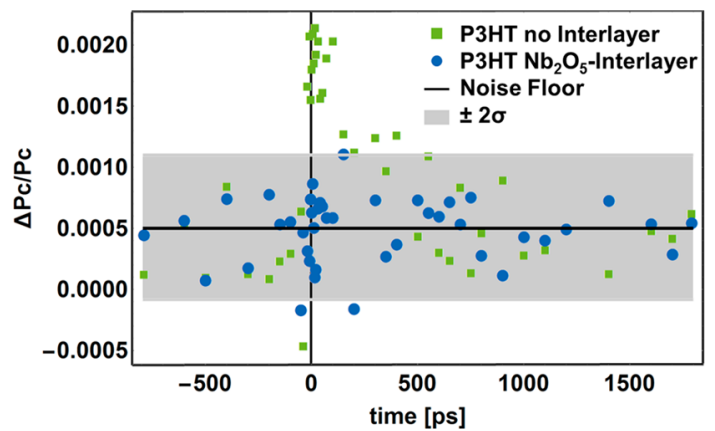

Figure 5. Pump-push photocurrent kinetics for $\mathrm{P} 3 \mathrm{HT}$ cells with and without the $\mathrm{Nb}_{2} \mathrm{O}_{5}$ interlayer. The pump-push photocurrent is much higher for devices without an interlayer, decaying on a time scale of approximately 200 ps. Solar cells with an interlayer show a pump-push current response indistinguishable from the noise level $( \pm 2 \sigma)$.

away from the $\mathrm{P} 3 \mathrm{HT}-$ metal oxide interface, thereby preventing the formation of BCPs. As a consequence, fewer charge carrier pairs recombine prior to extraction, which leads to a significant increase in $J_{\mathrm{sc}}$ (Figure 2).

\section{CONCLUSION}

To conclude, we have investigated the charge recombination mechanisms in $\mathrm{P} 3 \mathrm{HT}-\mathrm{TiO}_{2}$ hybrid solar cells and $\mathrm{PbSe} C \mathrm{CQ}-\mathrm{TiO}_{2}$ photovoltaic devices when an energy cascading interlayer of $\mathrm{Nb}_{2} \mathrm{O}_{5}$ is introduced. Using a rapid and scalable deposition technique for the fabrication of the $\mathrm{Nb}_{2} \mathrm{O}_{5}$ interlayer (AP-SALD), we find improved device performance in both types of devices mainly due to a suppression of nongeminate recombination. Interestingly, with the $\mathrm{Nb}_{2} \mathrm{O}_{5}$ interlayer present, the P3HT cells show a much greater improvement in short-circuit current density than the PbSe CQD cells ( $44 \%$ versus $25 \%$ improvement). We explain this phenomenon with the capability of $\mathrm{Nb}_{2} \mathrm{O}_{5}$ to passivate electron-accepting trap states on the $\mathrm{TiO}_{2}$ surface, which suppresses the trap-assisted (ShockleyRead-Hall-type) recombination that is prevalent in the P3HT devices. In PbSe CQD-based cells we argue that this effect is less dominant since we measure other nongeminate recombination channels to occur on faster time scales, rendering trap-assisted SRHtype recombination less important. Furthermore, using pump-push photocurrent spectroscopy we show that BCP formation in P3HT cells is virtually eliminated as a loss pathway upon introduction of the $\mathrm{Nb}_{2} \mathrm{O}_{5}$ interlayer. We note that our scalable and rapid deposition technique to fabricate stable, inorganic interlayers could be extended to further types of bilayer and nanostructured metal oxides to increase the efficiency of hybrid photovoltaics.

\section{EXPERIMENTAL SECTION}

Synthesis of $\mathrm{TiO}_{2} \mathrm{Nb}_{2} \mathrm{O}_{5}$ and $\mathrm{AlO}_{\mathbf{x}}$ Thin Films. $\mathrm{TiO}_{2}, \mathrm{Nb}_{2} \mathrm{O}_{5}$, and $\mathrm{AlO}_{\mathrm{x}}$ films were deposited on ITO/glass substrates at 300,300, and $150^{\circ} \mathrm{C}$, respectively, using AP-SALD. Substrates were sonicated in water, acetone, and 2-propanol prior to deposition. Titanium isopropoxide (heated to $110^{\circ} \mathrm{C}$ ), niobium ethoxide (heated to 
$205^{\circ} \mathrm{C}$ ), and trimethylaluminum (room temperature) (all SigmaAldrich) were used as the $\mathrm{Ti}, \mathrm{Nb}$, and Al precursors, respectively, with water as the oxidizing agent. Nitrogen was bubbled through the metallic precursors at $100 \mathrm{~mL} \mathrm{~min}^{-1}$ for deposition of $\mathrm{TiO}_{2}$ and $\mathrm{Nb}_{2} \mathrm{O}_{5}$ films, respectively, and $10 \mathrm{~mL} \mathrm{~min}^{-1}$ for $\mathrm{AlO}_{\mathrm{x}}$. The bubbling rate through the water was $50 \mathrm{~mL} \mathrm{~min}^{-1}$ for all $\mathrm{TiO}_{2}, \mathrm{Nb}_{2} \mathrm{O}_{5}$, and $\mathrm{AlO}_{\mathrm{x}}$ depositions. The resulting vapors in each bubbler were delivered to the head via separate carrier lines. For $\mathrm{TiO}_{2}$ and $\mathrm{Nb}_{2} \mathrm{O}_{5}$ depositions a flow of $500 \mathrm{~mL} \mathrm{~min}{ }^{-1}$ was used in the metal carrier line, $100 \mathrm{~mL} \mathrm{~min}^{-1}$ through the

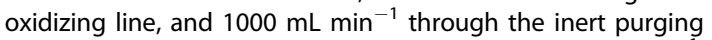
line. For $\mathrm{AlO}_{x}$, these flows were 100, 200, and $1500 \mathrm{~mL} \mathrm{~min}^{-1}$, respectively. The samples were scanned underneath the head at $50 \mathrm{~mm} \mathrm{~s}^{-1}$. Film thicknesses were measured using a Dektak profilometer.

Device Fabrication. $\mathrm{TiO}_{2}, \mathrm{Nb}_{2} \mathrm{O}_{5}$, and $\mathrm{AlO}_{x}$ layers were deposited by AP-SALD onto ITO/glass substrates. For P3HT cells, Sepiolid P200 P3HT (Rieke Metals, Inc.) was dissolved in chlorobenzene (Sigma-Aldrich) with a concentration of $15 \mathrm{mg} \mathrm{mL}^{-1}$ and stirred overnight at $40{ }^{\circ} \mathrm{C}$. Prior to coating with $\mathrm{P} 3 \mathrm{HT}$, the samples were sonicated in ethanol and then heated to $120^{\circ} \mathrm{C}$ for $10 \mathrm{~min}$. A $125 \mu \mathrm{L}$ amount of P3HT was spin-coated onto the films at $600 \mathrm{rpm}$ for $6 \mathrm{~s}$, followed by $1000 \mathrm{rpm}$ for $60 \mathrm{~s}$. Samples were then annealed at $150{ }^{\circ} \mathrm{C}$ in air for $15 \mathrm{~min}$, and contacts (ca. $7 \mathrm{~nm}$ $\mathrm{MoO}_{3}$ and $80 \mathrm{~nm} \mathrm{Ag}$ ) thermally evaporated.

For PbSe cells, all chemicals were purchased from SigmaAldrich, if not otherwise stated, and were anhydrous if available. The synthesis of $\mathrm{PbSe}$ quantum dots follows previous work. In summary, lead acetate trihydrate $(2.2 \mathrm{~g}, 5.8 \mathrm{mmol}, 99.999 \%)$ or lead(II) oxide (1.3 g, $5.8 \mathrm{mmol}, 99.999 \%)$ was degassed with OA (4.45 mL, technical grade, 90\%) in ODE (34 mL, technical grade, $90 \%$ ) at $110{ }^{\circ} \mathrm{C}$ under vacuum for $2 \mathrm{~h}$. Under inert atmosphere, the solution was then heated to $120{ }^{\circ} \mathrm{C}$, and the Se precursor solution, consisting of Se $(1.26 \mathrm{~g}, 16 \mathrm{mmol}$, 99.999\%) and diphenyl phosphine (16 $\mu \mathrm{L}, 98 \%)$ in tri- $n$ octylphosphine (16 mL, 97\%), was injected rapidly. After $10 \mathrm{~s}$ the reaction was quenched by the injecting of hexane and placing the flask into a water bath. The formed PbSe quantum dots were separated from the reaction solution by flocculating with an $n$-butanol/methanol mixture in a nitrogen-filled glovebox. Hexane, $n$-butanol, and methanol were used for two additional cleaning steps. Finally, the quantum dots were dispersed in octane and stored under nitrogen. To fabricate solar cells, the $\mathrm{TiO}_{2}$ - and $\mathrm{TiO}_{2} / \mathrm{Nb}_{2} \mathrm{O}_{5}$-coated ITO samples were transferred to a nitrogen-filled glovebox, and quantum dots (25 $\mathrm{mg} / \mathrm{mL}$ in octane) were deposited by a layer-by-layer technique. A thin layer of quantum dots was spin-cast on the films followed by dropping 1,3-benzenedithiol (BDT) in acetonitrile $(0.02 \mathrm{M})$ on the film to cross-link the quantum dots. Three seconds after BDT deposition the liquid was spun off followed by spinning cycles with pure acetonitrile and pure octane. This was repeated until the desired thickness $(150 \mathrm{~nm})$ was reached. Contacts $(\sim 7 \mathrm{~nm}$ $\mathrm{MoO}_{3}$ and $\sim 80 \mathrm{~nm} \mathrm{Au}$ ) were thermally evaporated.

Materials Characterization. X-ray Diffraction. Measurements were performed using a Bruker D8 theta/theta XRD system with $\mathrm{Cu} \mathrm{K} \alpha$ radiation $(\lambda=0.15418 \mathrm{~nm})$ and a LynxEye positionsensitive detector, scanning from $2 \theta=20^{\circ}$ to $75^{\circ}$.

Photoemission Spectroscopy. The samples $\left(\mathrm{TiO}_{2}\right.$ and $\mathrm{Nb}_{2} \mathrm{O}_{5}$ films on silicon wafer) were transferred to the ultrahigh-vacuum chamber (ESCALAB 250Xi) for UPS/XPS measurements. UPS measurements were performed using a double-differentially pumped He gas discharge lamp emitting $\mathrm{He} I$ radiation $(h v=$ $21.22 \mathrm{eV}$ ) with a pass energy of $2 \mathrm{eV}$. XPS measurements were carried out using an XR6 monochromated Al K $\alpha$ X-ray source ( $h v=1486.6 \mathrm{eV}$ ) with a $650 \mu \mathrm{m}$ spot size. $\mathrm{Ar}^{+}$ion gun etching was performed using an ion energy of $3000 \mathrm{eV}$.

UV-Vis Measurements. Absorbance measurements were performed using an Agilent/HP 8453 UV-vis spectrometer, and the band gap was determined through a Tauc plot.

Photovoltaic Measurements. Current Density-Voltage Characterization. Measurements were made using a Keithley 2636 source meter under an Oriel $92550 \mathrm{~A}$ solar simulator, at an intensity equivalent to $100 \mathrm{~mW} \mathrm{~cm}^{-2}$ after correcting for spectral mismatch. Mesh attenuators (ABET) were used to measure the light intensity dependence.
Photovoltage Decay. Measurements were carried out using a green $(525 \mathrm{~nm}$ ) light-emitting diode connected to a HewlettPackard $8116 \mathrm{~A}$ pulse/function generator producing a 750 and 15 ms square voltage pulse for $\mathrm{P} 3 \mathrm{HT}$ and $\mathrm{PbSe}$ cells, respectively. The voltage response from the solar cell was recorded using an Agilent DSO6052A digitalizing oscilloscope (input impedance $1 \mathrm{M} \Omega$ ). Measurements were taken with a white light bias of $33 \mathrm{~mW} \mathrm{~cm}^{-2}$.

Photothermal Deflection Spectroscopy. Measurements were performed on $\mathrm{TiO}_{2}$ and $\mathrm{TiO}_{2} / \mathrm{Nb}_{2} \mathrm{O}_{5}$ thin films $(\sim 90 \mathrm{~nm} \mathrm{TiO}$, $\sim 10 \mathrm{~nm} \mathrm{Nb} \mathrm{O}_{5}$ ) deposited on Spectrosil substrates. A detailed description of this technique can be found elsewhere. ${ }^{62}$

Transient Pump-Push Photocurrent Spectroscopy. A tunable titanium-sapphire oscillator system (Coherent, Chameleon Ultra II, $80 \mathrm{MHz}$ ) was used to directly generate infrared push pulses $(1100 \mathrm{~nm})$ and to pump an optical parametric oscillator (Coherent, OPO Compact) to generate visible pump pulses $(450 \mathrm{~nm})$. The pump beam frequency of $2 \mathrm{kHz}$ was selected using a commercial acousto-optic pulse picker (PulseSelect pulse picker from STFC), and the push line frequency was given by a homemade acousto-optic pulse selector at $1 \mathrm{kHz}$. Reference photocurrent from a photodiode was detected at the pump repetition frequency by a lock-in amplifier (Zurich Instruments HF2LI). The push beam's effect on the photocurrent was detected by the lock-in amplifier. A $\sim 0.5 \mathrm{~nJ}$ pump and a $\sim 0.1 \mu \mathrm{J}$ push pulse were focused into $a \sim 0.2 \mathrm{~mm}^{2}$ spot on the device with an objective lens.

Conflict of Interest: The authors declare no competing financial interest.

Supporting Information Available: The Supporting Information is available free of charge on the ACS Publications website at DOI: 10.1021/acsnano.5b05934.

Information outlining the material characterization and band structure calculation (PDF)

Acknowledgment. C.L.A. acknowledges the Sims Scholarship from the University of Cambridge. J.L.M.D. acknowledges funding from the European Research Council Advanced Investigator Grant NOVOX ERC-2009-adG247276ERC. M.L.B. thanks the German National Academic Foundation (Studienstiftung) and the Engineering and Physical Sciences Research Council Grant RG53717 KJZA/098 for funding. C.L.A. thanks A. Kursumovic for help and useful discussions. The data underlying this publication are available at https://www.repository.cam.ac.uk/handle/ $1810 / 252459$.

\section{REFERENCES AND NOTES}

1. Li, S.-S.; Chen, C.-W. Polymer-Metal-Oxide Hybrid Solar Cells. J. Mater. Chem. A 2013, 1, 10574.

2. Wu, G.; Li, Z.; Zhang, X.; Lu, G. Charge Separation and Exciton Dynamics at Polymer/ZnO Interface from FirstPrinciples Simulations. J. Phys. Chem. Lett. 2014, 5, 26492656.

3. Hsu, J. W. P.; Lloyd, M. T. Organic/Inorganic Hybrids for Solar Energy Generation. MRS Bull. 2010, 35, 422428.

4. Bouclé, J.; Ravirajan, P.; Nelson, J. Hybrid Polymer-Metal Oxide Thin Films for Photovoltaic Applications. J. Mater. Chem. 2007, 17, 3141.

5. Huynh, W. U.; Dittmer, J. J.; Alivisatos, A. P. Hybrid NanorodPolymer Solar Cells. Science 2002, 295, 2425-2427.

6. Weickert, J.; Dunbar, R. B.; Hesse, H. C.; Wiedemann, W.; Schmidt-Mende, L. Nanostructured Organic and Hybrid Solar Cells. Adv. Mater. 2011, 23, 1810-1828.

7. Beek, W. J. E.; Wienk, M. M.; Janssen, R. A. J. Hybrid Solar Cells from Regioregular Polythiophene and ZnO Nanoparticles. Adv. Funct. Mater. 2006, 16, 1112-1116.

8. Beek, W. J. E.; Wienk, M. M.; Janssen, R. A. J. Efficient Hybrid Solar Cells from Zinc Oxide Nanoparticles and a Conjugated Polymer. Adv. Mater. 2004, 16, 1009-1013.

9. Oosterhout, S. D.; Wienk, M. M.; van Bavel, S. S.; Thiedmann, R.; Jan Anton Koster, L.; Gilot, J.; Loos, J.; Schmidt, V.; Janssen, R. A. J. The Effect of Three-Dimensional 
Morphology on the Efficiency of Hybrid Polymer Solar Cells. Nat. Mater. 2009, 8, 818-824.

10. Oosterhout, S. D.; Koster, L. J. A.; van Bavel, S. S.; Loos, J.; Stenzel, O.; Thiedmann, R.; Schmidt, V.; Campo, B.; Cleij, T. J.; Lutzen, L.; et al. Controlling the Morphology and Efficiency of Hybrid ZnO:Polythiophene Solar Cells Via Side Chain Functionalization. Adv. Energy Mater. 2011, 1, 90-96.

11. Lin, Y.-Y.; Chu, T.-H.; Li, S.-S.; Chuang, C.-H.; Chang, C.-H.; Su, W.-F.; Chang, C.-P.; Chu, M.-W.; Chen, C.-W. Interfacial Nanostructuring on the Performance of Polymer/TiO2 Nanorod Bulk Heterojunction Solar Cells. J. Am. Chem. Soc. 2009, 131, 3644-3649.

12. Musselman, K. P.; Albert-Seifried, S.; Hoye, R. L. Z.; Sadhanala, A.; Muñoz-Rojas, D.; MacManus-Driscoll, J. L.; Friend, R. H. Improved Exciton Dissociation at Semiconducting Polymer:ZnO Donor:Acceptor Interfaces via Nitrogen Doping of ZnO. Adv. Funct. Mater. 2014, 24, 3562-3570.

13. Vaynzof, Y.; Bakulin, A. A.; Gélinas, S.; Friend, R. H. Direct Observation of Photoinduced Bound Charge-Pair States at an Organic-Inorganic Semiconductor Interface. Phys. Rev. Lett. 2012, 108, 246605.

14. Haeldermans, I.; Vandewal, K.; Oosterbaan, W. D.; Gadisa, A.; D'Haen, J.; Van Bael, M. K.; Manca, J. V.; Mullens, J. Ground-State Charge-Transfer Complex Formation in Hybrid Poly(3-Hexyl thiophene):Titanium Dioxide Solar Cells. Appl. Phys. Lett. 2008, 93, 1-4.

15. Bansal, N.; Reynolds, L. X.; MacLachlan, A.; Lutz, T.; Ashraf, R. S.; Zhang, W.; Nielsen, C. B.; McCulloch, I.; Rebois, D. G.; Kirchartz, T.; et al. Influence of Crystallinity and Energetics on Charge Separation in Polymer-Inorganic Nanocomposite Films for Solar Cells. Sci. Rep. 2013, 3, 1531.

16. Vaynzof, Y.; Kabra, D.; Zhao, L.; Ho, P. K. H.; Wee, A. T. S.; Friend, R. H. Improved Photoinduced Charge Carriers Separation in Organic-Inorganic Hybrid Photovoltaic Devices. Appl. Phys. Lett. 2010, 97, 033309.

17. Pachoumi, O.; Bakulin, A. A.; Sadhanala, A.; Sirringhaus, H.; Friend, R. H.; Vaynzof, Y. Improved Performance of $\mathrm{ZnO}$ / Polymer Hybrid Photovoltaic Devices by Combining Metal Oxide Doping and Interfacial Modification. J. Phys. Chem. C 2014, 118, 18945-18950.

18. Lin, Y. Y.; Lee, Y. Y.; Chang, L.; Wu, J. J.; Chen, C. W. The Influence of Interface Modifier on the Performance of Nanostructured ZnO/Polymer Hybrid Solar Cells. Appl. Phys. Lett. 2009, 94, 063308.

19. Lin, Y. Y.; Chu, T. H.; Chen, C. W.; Su, W. F. Improved Performance of Polymer/TiO2 Nanorod Bulk Heterojunction Photovoltaic Devices by Interface Modification. Appl. Phys. Lett. 2008, 92, 053312.

20. Shen, Q.; Ogomi, Y.; Das, S. K.; Pandey, S. S.; Yoshino, K.; Katayama, K.; Momose, H.; Toyoda, T.; Hayase, S. Huge Suppression of Charge Recombination in P3HT-ZnO Organic-inorganic Hybrid Solar Cells by Locating Dyes at the ZnO/P3HT Interfaces. Phys. Chem. Chem. Phys. 2013, 15,14370

21. Ruankham, P.; Macaraig, L.; Sagawa, T.; Nakazumi, H.; Yoshikawa, S. Surface Modification of ZnO Nanorods with Small Organic Molecular Dyes for Polymer-Inorganic Hybrid Solar Cells. J. Phys. Chem. C 2011, 115, 2380923816.

22. Dorman, J. A.; Weickert, J.; Reindl, J. B.; Putnik, M.; Wisnet, A.; Noebels, M.; Scheu, C.; Schmidt-Mende, L. Control of Recombination Pathways in TiO 2 Nanowire Hybrid Solar Cells Using Sn 4+ Dopants. J. Phys. Chem. C 2014, 118, 16672-16679.

23. Tan, Z. K.; Johnson, K.; Vaynzof, Y.; Bakulin, A. A.; Chua, L. L.; Ho, P. K. H.; Friend, R. H. Suppressing Recombination in Polymer Photovoltaic Devices via Energy-Level Cascades. Adv. Mater. 2013, 25, 4131-4138.

24. Heidel, T. D.; Hochbaum, D.; Sussman, J. M.; Singh, V.; Bahlke, M. E.; Hiromi, I.; Lee, J.; Baldo, M. A. Reducing Recombination Losses in Planar Organic Photovoltaic Cells Using Multiple Step Charge Separation. J. Appl. Phys. 2011, 109, 104502
25. Hsieh, C. H.; Cheng, Y. J.; Li, P. J.; Chen, C. H.; Dubosc, M.; Liang, R. M.; Hsu, C. S. Highly Efficient and Stable Inverted Polymer Solar Cells Integrated with a Cross-Linked Fullerene Material as an Interlayer. J. Am. Chem. Soc. 2010, 132, 4887-4893.

26. Ihn, S.-G.; Lim, Y.; Yun, S.; Park, I.; Park, J.-H.; Chung, Y.; Bulliard, X.; Chang, J.; Choi, H.; Park, J. H.; et al. Enhancement of Power Conversion Efficiency in a Polymer Solar Cell Using a Work-Function-Controlled TimSinOx Interlayer. J. Mater. Chem. A 2013, 2, 2033-2039.

27. Chandiran, A. K.; Nazeeruddin, M. K.; Graetzel, M. The Role of Insulating Oxides in Blocking the Charge Carrier Recombination in Dye-Sensitized Solar Cells. Adv. Funct. Mater. 2014, 24, 1615-1623.

28. Ravirajan, P.; Peiró, A. M.; Nazeeruddin, M. K.; Graetzel, M.; Bradley, D. D. C.; Durrant, J. R.; Nelson, J. Hybrid Polymer/ Zinc Oxide Photovoltaic Devices with Vertically Oriented ZnO Nanorods and an Amphiphilic Molecular Interface Layer. J. Phys. Chem. B 2006, 110, 7635-7639.

29. Lee, Y. L.; Lo, Y. S. Highly Efficient Quantum-Dot-Sensitized Solar Cell Based on Co-Sensitization of $\mathrm{CdS} / \mathrm{CdSe}$. Adv. Funct. Mater. 2009, 19, 604-609.

30. Spoerke, E. D.; Lloyd, M. T.; McCready, E. M.; Olson, D. C.; Lee, Y. J.; Hsu, J. W. P. Improved Performance of Poly(3-hexylthiophene)/Zinc Oxide Hybrid Photovoltaics Modified with Interfacial Nanocrystalline Cadmium Sulfide. Appl. Phys. Lett. 2009, 95, 213506.

31. Goh, C.; Scully, S. R.; McGehee, M. D. Effects of Molecular Interface Modification in Hybrid Organic-Inorganic Photovoltaic Cells. J. Appl. Phys. 2007, 101, 114503.

32. Munoz-Rojas, D.; MacManus-Driscoll, J. Spatial Atmospheric Atomic Layer Deposition: A New Laboratory and Industrial Tool for Low-Cost Photovoltaics. Mater. Horiz. 2014, 1, 314-320.

33. Schultze, J. W.; Lohrengel, M. M. Stability, Reactivity and Breakdown of Passive Films. Problems of Recent and Future Research. Electrochim. Acta 2000, 45, 2499-2513.

34. Pore, V.; Rahtu, A.; Leskelä, M.; Ritala, M.; Sajavaara, T.; Keinonen, J. Atomic Layer Deposition of Photocatalytic TiO2 Thin Films from Titanium Tetramethoxide and Water. Chem. Vap. Deposition 2004, 10, 143-148.

35. Blanquart, T.; Kukli, K.; Niinisto, J.; Longo, V.; Heikkila, M.; Ritala, M.; Leskela, M. Optical and Dielectric Characterization of Atomic Layer Deposited Nb205 Thin Films. ECS Solid State Lett. 2012, 1, N1-N3.

36. Blanquart, T.; Niinistö, J.; Heikkilä, M.; Sajavaara, T.; Kukli, K.; Puukilainen, E.; Xu, C.; Hunks, W.; Ritala, M.; Leskelä, M. Evaluation and Comparison of Novel Precursors for Atomic Layer Deposition of Nb2O5 Thin Films. Chem. Mater. 2012, 24, 975-980.

37. Ehrler, B.; Musselman, K. P.; Böhm, M. L.; Morgenstern, F. S. F.; Vaynzof, Y.; Walker, B. J.; MacManus-Driscoll, J. L.; Greenham, N. C. Preventing Interfacial Recombination in Colloidal Quantum Dot Solar Cells by Doping the Metal Oxide. ACS Nano 2013, 7, 4210-4220.

38. Tang, H.; Levy, F.; Berger, H. Urbach Tail of Anatase TiO2. Phys. Rev. B: Condens. Matter Mater. Phys. 1995, 52, 2-5.

39. Sanjinés, R.; Tang, H.; Berger, H.; Gozzo, F.; Margaritondo, G.; Lévy, F. Electronic Structure of Anatase $\mathrm{TiO} 2$ Oxide. J. Appl. Phys. 1994, 75, 2945.

40. Hoye, R. L. Z.; Ehrler, B.; Böhm, M. L.; Muñoz-Rojas, D.; Altamimi, R. M.; Alyamani, A. Y.; Vaynzof, Y.; Sadhanala, A.; Ercolano, G.; Greenham, N. C.; et al. Improved Open-Circuit Voltage in ZnO-PbSe Quantum Dot Solar Cells by Understanding and Reducing Losses Arising from the $\mathrm{ZnO}$ Conduction Band Tail. Adv. Energy Mater. 2014, 4, 1301544.

41. Jo, H. J.; Nam, J. E.; Kim, D.-H.; Kang, J.-K. Improved Performance of Dye-Sensitized Solar Cells with Novel Conjugated Organic Dye Using Aluminum Oxide-Coated Nanoporous Titanium Oxide Films. J. Power Sources 2014, 249, 385-391.

42. Noma, Y.; Kado, T.; Ogata, D.; Hara, Y.; Hayase, S. Surface State Passivation Effect for Nanoporous TiO2 Electrode Evaluated by Thermally Stimulated Current and Application 
to All-Solid State Dye-Sensitized Solar Cells. Jpn. J. Appl. Phys. 2008, 47, 505-508.

43. Wang, R. Y.; Feser, J. P.; Lee, J. S.; Talapin, D. V.; Segalman, R.; Majumdar, A. Enhanced Thermopower in PbSe Nanocrystal Quantum Dot Superlattices. Nano Lett. 2008, 8, 2283-2288.

44. Garcia-Belmonte, G.; Munar, A.; Barea, E. M.; Bisquert, J.; Ugarte, I.; Pacios, R. Charge Carrier Mobility and Lifetime of Organic Bulk Heterojunctions Analyzed by Impedance Spectroscopy. Org. Electron. 2008, 9, 847-851.

45. Kirchartz, T.; Nelson, J. Meaning of Reaction Orders in Polymer:Fullerene Solar Cells. Phys. Rev. B: Condens. Matter Mater. Phys. 2012, 86, 165201.

46. Koster, L. J. A.; Mihailetchi, V. D.; Ramaker, R.; Blom, P. W. M. Light Intensity Dependence of Open-Circuit Voltage of Polymer:Fullerene Solar Cells. Appl. Phys. Lett. 2005, 86, 123509.

47. Cowan, S. R.; Leong, W. L.; Banerji, N.; Dennler, G.; Heeger, A. J. Identifying a Threshold Impurity Level for Organic Solar Cells: Enhanced First-Order Recombination via Well-Defined PC84BM Traps in Organic Bulk Heterojunction Solar Cells. Adv. Funct. Mater. 2011, 21, 30833092.

48. Kirchartz, T.; Deledalle, F.; Tuladhar, P. S.; Durrant, J. R.; Nelson, J. On the Differences Between Dark and Light Ideality Factor in Polymer:Fullerene Solar Cells. J. Phys. Chem. Lett. 2013, 4, 2371-2376.

49. Rau, U. Tunneling-Enhanced Recombination in $\mathrm{Cu}(\mathrm{In}, \mathrm{Ga})$ Se2 Heterojunction Solar Cells. Appl. Phys. Lett. 1999, 74, 111.

50. Steingrube, S.; Breitenstein, O.; Ramspeck, K.; Glunz, S.; Schenk, A.; Altermatt, P. P. Explanation of Commonly Observed Shunt Currents in c-Si Solar Cells by Means of Recombination Statistics Beyond the Shockley-Read-Hall Approximation. J. Appl. Phys. 2011, 110, 1-10.

51. Breitenstein, O.; Altermatt, P.; Ramspeck, K.; Green, M. A.; Zhao, J.; Schenk, A. Interpretation of the Commonly Observed I-V Characteristics of c-Si Cells Having Ideality Factor Larger than Two. In Interpretation of the Commonly Observed I-V Characteristics of C-Si Cells Having Ideality Factor Larger than Two, WCPEC-4; 2007; Vol. 1, pp 879884.

52. Alivisatos, A. P. Semiconductor Clusters, Nanocrystals, and Quantum Dots. Science (Washington, DC, U. S.) 1996, 271, 933-937.

53. Böhm, M. L.; Jellicoe, T. C.; Rivett, J. P. H.; Sadhanala, A.; Davis, N. J. L. K.; Morgenstern, F. S. F.; Gödel, K. C.; Govindasamy, J.; Benson, C. G. M.; Greenham, N. C.; et al. Size and Energy Level Tuning of Quantum Dot Solids via a Hybrid Ligand Complex. J. Phys. Chem. Lett. 2015, 6, 3510-3514.

54. Klimov, V. I. Optical Gain and Stimulated Emission in Nanocrystal Quantum Dots. Science (Washington, DC, U. S.) 2000, 290, 314-317.

55. Klimov, V. I. Quantization of Multiparticle Auger Rates in Semiconductor Quantum Dots. Science (Washington, DC, U. S.) 2000, 287, 1011-1013.

56. Schaller, R.; Klimov, V. High Efficiency Carrier Multiplication in PbSe Nanocrystals: Implications for Solar Energy Conversion. Phys. Rev. Lett. 2004, 92, 1-4.

57. Ellingson, R. J.; Beard, M. C.; Johnson, J. C.; Yu, P.; Micic, O. I.; Nozik, A. J.; Shabaev, A.; Efros, A. L. Highly Efficient Multiple Exciton Generation in Colloidal PbSe and PbS Quantum Dots. Nano Lett. 2005, 5, 865-871.

58. Kirchartz, T.; Pieters, B. E.; Kirkpatrick, J.; Rau, U.; Nelson, J. Recombination via Tail States in Polythiophene:Fullerene Solar Cells. Phys. Rev. B: Condens. Matter Mater. Phys. 2011, 83, 1-13.

59. Gao, F.; Li, Z.; Wang, J.; Rao, A.; Howard, I. A.; Abrusci, A.; Massip, S.; McNeill, C. R.; Greenham, N. C. Trap-Induced Losses in Hybrid Photovoltaics. ACS Nano 2014, 8, 32133221.

60. Bakulin, A. A.; Rao, A.; Vaynzof, Y.; Gelinas, S.; Pavelyev, V. G.; van Loosdrecht, P. H. M.; Pshenichnikov, M. S.; Niedzialek, D.; Cornil, J.; Beljonne, D.; et al. Ultrafast
Pump-Push Photocurrent Spectroscopy of Organic Photoconversion Systems. EPJ Web Conf. 2013, 41, 05020.

61. Sharma, A. C. Size-Dependent Energy Band Gap and Dielectric Constant Within the Generalized Penn Model Applied to a Semiconductor Nanocrystallite. J. Appl. Phys. 2006, 100, 084301.

62. Kronemeijer, A. J.; Pecunia, V.; Venkateshvaran, D.; Nikolka, M.; Sadhanala, A.; Moriarty, J.; Szumilo, M.; Sirringhaus, H. Two-Dimensional Carrier Distribution in Top-Gate Polymer Field-Effect Transistors: Correlation Between Width of Density of Localized States and Urbach Energy. Adv. Mater. 2014, 26, 728-733. 